\title{
Economics
}

2019; 8(3): 114-127

$\mathrm{http}: / / \mathrm{www} . \mathrm{sciencepublishinggroup.com} / \mathrm{j} / \mathrm{eco}$

doi: 10.11648/j.eco.20190803.14

ISSN: 2376-659X (Print); ISSN: 2376-6603 (Online)

\section{The Trends of the Average Propensities to Consume and Urban-rural Consumption Inequality in China}

\author{
Chen Zongsheng ${ }^{1}$, Wu Zhiqiang ${ }^{2}$ \\ ${ }^{1}$ Nankai Institute of Economics, Nankai University, Tianjin, China \\ ${ }^{2}$ Party School of the Jiangxi Provincial Committee of CPC, Nanchang, China
}

Email address:

zschen@nankai.edu.cn (Chen Zongsheng)

\section{To cite this article:}

Chen Zongsheng, Wu Zhiqiang. The Trends of the Average Propensities to Consume and Urban-rural Consumption Inequality in China. Economics. Vol. 8, No. 3, 2019, pp. 114-127. doi: 10.11648/j.eco.20190803.14

Received: December 4, 2018; Accepted: September 6, 2019; Published: September 24, 2019

\begin{abstract}
As the average propensities to consume between urban and rural residents are different, the consumption inequality and the income inequality inverted-U curves are different in the process of urbanization (economic development). It shows urban-rural consumption inequality passes the turning point of the inverted-U curve during 2000 and 2002, which is about 4-6 years ahead of the urban-rural income inequality inverted-U curve. The urbanization rate (economic development level) of urban-rural consumption inequality is lower than that of urban-rural income inequality at their turning points, while the urban-rural consumption equality at its turning point is larger than the urban-rural income equality at its turning point. This paper argues that, on the premise that the urban-rural income inequality is certain, it can improve the actual welfare of residents by reducing the urban-rural consumption equality. The feasible measures may be increasing the residents' (especially rural residents') average propensity to consume.
\end{abstract}

Keywords: Average Propensity to Consume, Consumption Inequality, Income Inequality, Urbanization

\section{Introduction}

According to the "inverted-U" theory of income distribution, income inequality usually shows an "inverted- $U$ " change trend that first rises and then falls during the transformation of economic development from traditional dual economy to developed economy [1-3]. Since income is the most important factor that restricts consumption ${ }^{1}$, the consumption will be equal

1 Residents' consumption is affected by many factors, but the influence of income on consumption undoubtedly plays a decisive role, which is discussed and reflected in consumption theories. Keynes's absolute consumption theory argues that there is a basic rule, that is, as income increases, so does consumption, but not by as much as income [4]. According to the relative income consumption theory, in the long run, the increase or decrease of income will lead to the increase or decrease of consumption [5]. Life cycle consumption theory believes that people will plan their income and arrange their living consumption expenditure for a longer period [6]. They allocate income for consumption throughout the life cycle to achieve their optimal allocation of consumption throughout the life cycle. According to the theory of permanent income consumption, short-term income adjustment will not affect consumption fully immediately, while permanent income growth will increase consumption [7]. All in all, these existing theories are based on the significant impact of income on consumption.

Many studies have also shown that income has a significant positive effect on to income if the influence of accumulation and saving is not taken into account. It is not difficult to deduce that the change of consumption inequality should be the same as that of income inequality in the same economic development process, and it will also show a similar trend of "inverted-U". In other words, consumption inequality and income inequality have the same

consumption. The higher the income is, the greater the increase in consumer spending $[8,9]$. Raising residents' income can promote consumption demand [10]. Some researchers also study the income and consumption of urban or rural residents. Income has a positive impact on the consumption of urban residents through establishing the gray relational model [11]. The focus of strengthening rural consumption capacity should be on improving rural residents' income [12]. The fundamental way to increase rural residents' consumption is to increase rural residents' income [13]. Some researchers also found that different income sources have different effects on consumption. For urban residents, the consumption effect of wage income and transfer income is greater, while for rural residents, the consumption effect of wage income and operating income is greater [14]. Rural operating income has a higher influence on rural consumption, while the influence of wage income gradually decreases [15]. To expand the consumption demand of residents, the transfer income and property income of residents should be increased in the short term, and the wage income and operational income of urban and rural residents should be increased in the long term [16]. Although the emphasis of these empirical studies varies, they all show that income does have an important impact on consumption. 
internal mechanism, and the change trend of income inequality and consumption inequality should be roughly the same. Studies have confirmed that factors influencing income inequality, such as labor difference, residual-livelihood ratio, capital accumulation, urban-rural difference and urbanization, also affect consumption inequality $[2,17]$. Therefore, while affecting the change of income inequality, these factors also influence the change of consumption inequality, which leads to the similar "inverted-U shaped" change of urban-rural consumption inequality.

However, further analysis after introducing consumption propensity factors shows that the change of urban-rural consumption inequality is not equal to the change of urban-rural income inequality, and they may be just similar in form but different in the variation range and turning direction. The "inverted-U shaped" curve of urban-rural consumption inequality may be higher or lower than the urban-rural income inequality in the process of economic development, and the turning point of their respective changes will not be completely consistent. The main reason for such differences is that the variation of consumption inequality is not only affected by the same factors as income inequality, but also affected by the influence of consumption propensity including the average propensity to consume and the marginal propensity to consume. This paper focuses on the impact of average propensity to consume. The average propensity to consume refers to the proportion of consumption in one's income. Due to restrictions of various reasons, the proportion of consumption in urban and rural residents' income cannot be the same, so it will inevitably lead to different heights and turning points of the urban-rural consumption inequality curve and the urban-rural income inequality curve.

It is of certain practical significance to study the variation difference between urban-rural consumption inequality and urban-rural income inequality. Firstly, the history of economics tells us that the difference between urban-rural consumption inequality and income inequality may be little at the current situation of low income level as well as residents' savings and accumulation not high. But the difference between urban-rural consumption inequality and income inequality will be more obvious in the future when income level increases and saving and accumulation get to a higher level. This is the result and significance of these two variations. Secondly, with the transformation of economic growth impetus, people pay more and more attention to the effect of consumption growth in promoting the expansion of domestic demand, differences in consumption level and total consumption. Therefore, it is more important than ever to study the trend of urban-rural consumption and the changes of consumption inequality, and to provide some cognitive help for the power conversion at least. Finally, the income obtained by residents can only represent their possible and potential consumption ability, while the actual consumption level can truly reflect the residents' actual welfare situation. Thus, the urban-rural consumption inequality can more directly reflect the differences in the actual welfare between urban and rural residents. Therefore, narrowing the urban-rural consumption inequality through reform and development can reduce the urban-rural difference and let urban and rural residents share the fruits of economic development fairly.

In the following discussion, we will explain the factors that cause the difference between urban and rural residents' average propensity to consume. Then we will discuss the impact of the average propensity to consume on urban-rural consumption inequality in the process of urbanization. Also we will explain the discrepancy between the variation curve of urban-rural consumption inequality and urban-rural income inequality and put forward two hypotheses about the discrepancy between urban-rural consumption inequality and urban-rural income inequality. Finally, we will test the above hypothesis using data from 1980-2014 in China and give short conclusion and recommendations.

\section{Factors That Cause the Difference Between Urban and Rural Residents' Average Propensity to Consume}

Literature review shows that many scholars have studied various factors influencing the consumption and average propensity to consume of urban and rural residents [18-22]. Among them, most studies emphasize the importance of the income factor and consider that the difference of income level is the important reason for the difference of urban and rural consumption level $^{2}$. For example, the low income of rural residents leads to the insufficient consumption of rural residents in China [23]. There are four other factors influencing the difference in average propensity to consume between urban and rural areas:

First, different social security systems lead to different consumption propensities in urban and rural areas. The social security system in China originates from the dual social structure. That is, on the basis of the state owned system and collective public ownership system in urban and rural areas respectively, China also implements the social security system Characterized by dual household registration system accordingly. From the status quo of this system, the social security of urban residents is superior to that of rural ones. In quite a long period, the urban residents most of whom work in the state-owned factories, once lose their jobs, may lose all their income sources. Therefore, the state has implemented the system security of housing, medical care, pension and education and so on to the urban residents. In addition, the precautionary savings of urban residents are higher because of their higher incomes. For rural residents, they realize the social security function mainly through land management. So

\footnotetext{
2 Due to the high correlation between consumption and income, when the income inequality changes in a social group, it will inevitably lead to the change of consumption inequality of different income earners. Some studies have noticed the correlation between income inequality and consumption inequality, and found that there is a dynamic correlation between urban-rural income inequality and urban-rural consumption inequality [23, 24]. Urban-rural income inequality will expand urban-rural consumption inequality. Urban-rural income inequality and urban-rural consumption inequality show a long-term trend of increase [25]. They suggest to reduce the income inequality to restrain the expansion of consumption inequality $[26,27]$.
} 
their social security lacks stability and has more obvious differences than urban residents as the agricultural product prices are affected by market volatility and climate factors, combining with the temporary income increase of migrant workers [28]. Of course, only sound social security can support and encourage residents to consume normally. Otherwise, they will reduce consumption for an uncertain future. From the current situation of China, the impact of different social security systems on the consumption of urban and rural residents is very obvious, thus causing the average propensity to consume of urban residents in China to be higher than that of rural residents for a long time.

Second, different consumption concepts lead to different consumption propensities in urban and rural areas. Chinese people have the virtue of thrift since ancient times and have been in the state of material shortage for a long time. This causes the general economic concept of frugality and preference to savings ${ }^{3}$. With the improvement of China's economic development level, the dual system deepens the differences between urban and rural residents' consumption concepts. The cash income of urban residents is high, and the consumption concept and level are naturally higher too. Especially in recent years, due to the promotion of e-commerce and consumer credit business, the consumption concept of the new generation of Chinese urban residents has begun to change gradually, and consumer credit is more and more accepted by urban residents. However, in the vast rural areas, there is a shortage of current income as residents' cash income mainly comes from the completion of the annual production process. So rural residents are still accustomed to the traditional non-borrowing consumption model and consumption is not effectively released due to the imprisonment of concepts. Different consumption habits based on different materials are one of the reasons why the average propensity to consume of urban residents is higher than that of rural ones.

Third, the change of consumption structure leads to the difference of average consumption propensities between urban and rural areas. Some scholars believe that the consumption structure of China's urban residents has begun to enter the transition period and the structure of traditional consumer goods is close to saturation, which cannot fully meet the consumption demand of urban residents. A new consumption structure needs to be formed. However, the structure of rural consumer goods is still traditional $[31,32]$. This leads to different consumption propensities between urban and rural residents in China. From the perspective of consumption and income level of urban and rural areas, urban residents may be in the transformation period of consumption structure update and farmers still have huge demand for the consumption of traditional commodities. This difference in consumption structure may lead to the average propensity to consume of rural residents higher than that of urban residents at a certain stage after economic development to a certain level.

3 This concept is in favor of stable development of China's economy in the early stage. But with the improvement of income level and the enrichment of materials, it restricts the consumption level of residents and easily leads to the situation of overproduction $[29,30]$.
Fourth, macroeconomic environment, prices, interest rates and other factors will also affect consumption. The fluctuation of these factors will affect people's income expectation, which will change people's consumption propensity. However, the urban and rural residents have different tolerance and sensitivity to these fluctuations due to various reasons. When the macro economy tends to go down, prices rise and people's expected income will decline, the urban residents will be more sensitive than rural residents. Thus they will reduce their expenditure, leading to a decline in the average propensity to consume. When interest rates and the return on savings rise, urban residents react more quickly than rural ones, favoring savings and lowering their average propensity to consume.

The average consumption propensities of urban and rural areas in China cannot be exactly the same because of these factors. Furthermore, such differences in urban and rural consumption trends also change at different stages of development. In the early stage of economic development, the social security and income level of urban residents are higher than that of rural ones. Their average propensity to consume will also be higher than that of rural residents. With the further improvement of income level to a certain stage, urban residents are restricted by the traditional consumption structure. The improvement of their consumption level is restrained. At the same time, the improvement of rural residents' income and social security level promotes the improvement of rural residents' consumption, which leads to the fact that the average propensity to consume of rural residents may be greater than that of urban residents.

In a word, restricted by different economic and social conditions, urban and rural residents' average propensity to consume are different. It also changes at different stages of economic development, resulting in the variation of the difference curve of urban and rural consumption.

\section{Variation of Urban-rural Consumption Inequality in the Process of Urbanization}

\subsection{The "Inverted-U Shaped" Trend of Urban-rural Consumption Inequality in the Process of Urbanization}

Ignoring the consumption propensity, this paper first focuses on how the consumption inequality presents an inverted-U shaped trend similar to the income inequality in the process of urbanization. Many scholars have explained how the transformation of urban and rural sectors in the process of urbanization leads to the "inverted-U" change of income inequality [2, 3, 17, 33, 34]. By referring to these mature theoretical analysis4, we can accurately explain the "inverted-U"

4 Chen zongsheng proves that when the income inequality inner urban and rural departments was zero, the departmental population transformation as a function of per capita income, namely the process of urbanization, would inevitably lead to an inverted-U shaped curve of income inequality [1]. The structure change between urban and rural sectors has a positive impact on income inequality in the early stage of economic development and a negative impact in the later stage of economic development. Zhou yunbo further gives the rigorous derivation of another 
change of consumption inequality in the urbanization process of population transfer from low-income sector (rural sector) to high-income sector (urban sector) as long as income level is replaced by consumption level. Therefore, it can be assumed that the consumption level of each resident in the urban and rural departments is the same, and the urban-rural consumption ratio is $Z$, and $Z>1$. According to the gap value method $^{5}$, the Gini coefficient of total consumption is equal to the difference between the total consumption share of urban population in the total consumption of society and urban population in the total population of society. So the urbanization rate at the turning point of urban-rural consumption inequality can be calculated as $P_{Z}^{*}$ :

$$
P_{Z}^{*}=\frac{1}{Z^{\frac{1}{2}}+1}
$$

Here, $P_{Z}^{*}$ refers to the urbanization rate when the urban-rural consumption inequality is the largest. Therefore, we can speculate the corresponding social maximum urban-rural consumption inequality consistent with the urbanization rate of this population. Namely, the Gini coefficient of the total consumption level constituted by the two sectors, denoted as $G_{Z}^{*}$ :

$$
G_{Z}^{*}=\frac{Z^{\frac{1}{2}}-1}{Z^{\frac{1}{2}}+1}
$$

Equation (2) indicates that when the urbanization rate is lower than $P_{Z}^{*}$, the total urban-rural consumption inequality increases with the increase of urban population. When the urbanization rate is equal to $P_{Z}^{*}$, the total difference between urban and rural consumption reaches the maximum, which is $G_{Z}^{*}$. When the urbanization rate is higher than $P_{Z}^{*}$, the total difference of urban and rural consumption gradually decreases. Therefore, it can be concluded that the urban-rural consumption inequality show an inverted- $U$ shaped change trend that first increases and then decreases which is similar to changes of urban-rural income inequality with the constant progress of urbanization. 6 That is to say, in the process of urbanization, as long as the consumption level of urban residents is greater than that of rural residents, the consumption inequality will show an inverted-U shaped trend

mathematical method, and explains how the urbanization process leads to the income inequality "inverted-U shaped" change under certain internal income inequality [17].

5 This method has been applied in some articles $[1,17]$. The formula of "gap value method" to calculate urban-rural income inequality and urban and rural consumption is shown in Part 4 in this paper. As the internal inequalities of urban and rural area do not take into account, urban-rural income inequality and urban-rural consumption inequality will be lower than the overall income inequality.

6 Equation (1) equation (2) also logically show the turning point of urban-rural consumption inequality when the population of high-income sectors shifts to low-income sectors in the process of reverse urbanization. But it does not accord with actual economic situation. So we ignore it. that first rises and then falls in the process of urbanization. In a country with such urban-rural dual economic system like China, economic development is often accompanied by the transformation of urban-rural dual structure, The continuous advancement of urbanization. Their change direction is basically the same. The process of improving the level of urbanization is also a process of advancing towards a higher level of economic development. In the following analysis, urbanization is still taken as the main indicator of economic development. Based on this, this paper proposes the first inferential hypothesis.

Hypothesis 1: In the process of economic development, urbanization as a basic factor restricts the change of urban-rural consumption inequality. Urban-rural consumption inequality presents an inverted-U shaped change process similar to the urban-rural income inequality.

\subsection{Differences Between the Urban-rural Consumption Inequality Curve and the Urban-rural Income Inequality Curve}

Next, we introduce the urban-rural average propensity to consume to examine its influence on the variation curve of urban-rural consumption inequality. Considering the differences in urban-rural consumption propensities, it is impossible for the urban-rural consumption ratio to be equal to the urban-rural income ratio. Also it will lead to the difference between the "inverted-U shaped" change trend of urban-rural consumption inequality and the "inverted-U shaped" change trend of urban-rural income inequality, including different paths and turning points. For the convenience of analysis, let the consumption function of urban residents be $c_{u}=c_{u}(y)$, and the consumption function of rural residents be $c_{r}=c_{r}(y)$. The consumption function satisfying the character that consumption is a increasing function of income. Suppose that the income of urban residents is $y_{u}$, that of rural residents is $y_{r}$, and $y_{u}>y_{r}$, then the consumption amount corresponding to the income of urban and rural residents is $c_{u}=c_{u}\left(y_{u}\right), c_{r}=c_{r}\left(y_{r}\right)$, and $c_{u}>c_{r}$. Under these assumption, the discussion is divided into four cases.

Firstly, when the average propensity to consume of urban residents is equal to that of rural residents in the process of urbanization, the "inverted-U" curve of urban-rural consumption difference and that of urban-rural income difference is coincident.

$$
\begin{aligned}
& \text { Because } \frac{c_{u}}{y_{u}}=\frac{c_{r}}{y_{r}} \text {, we have: } \\
& \qquad Z=\frac{c_{u}}{c_{r}}=\frac{y_{u}}{y_{r}}=X
\end{aligned}
$$

Here, $\frac{y_{u}}{y_{r}}=X$ is the urban-rural income ratio. It can be seen from equation (3) that the urban-rural consumption ratio equals to the urban-rural income ratio when the average propensity to consume of urban and rural residents is equal. It can be further concluded that: 


$$
\begin{gathered}
P_{Z}^{*}=\frac{1}{Z^{\frac{1}{2}}+1}=\frac{1}{X^{\frac{1}{2}}+1}=P_{X}^{*} \\
G_{Z}^{*}=\frac{Z^{\frac{1}{2}}-1}{Z^{\frac{1}{2}}+1}=\frac{X^{\frac{1}{2}}-1}{X^{\frac{1}{2}}+1}=G_{X}^{*}
\end{gathered}
$$

Among them, $P_{X}^{*}$ is the urbanization rate when the urban-rural income inequality is the largest, which is equivalent to $P_{Z}^{*}$ when the urban-rural consumption inequality is the largest; $G_{X}^{*}$ represents the Gini coefficient at the turning point of the "inverted-U" curve of the urban-rural income inequality, which is equivalent to the Gini coefficient $G_{Z}^{*}$ at the turning point of the urban-rural consumption inequality curve. Other symbols are the same as above.

From equation (4) and equation (5) we can obtain that: under the condition of the equivalence between urban and rural residents' average propensity to consume, along with the advancement of urbanization, the "inverted-U shaped" trend of Gini coefficient of urban-rural consumption inequality is the same to that of urban-rural income inequality. The turning points both appear at the same rate of urbanization. Gini coefficient of consumption inequality $G_{Z}^{*}$ and income inequality $G_{X}^{*}$ are equal at their turning points. In other words, under the assumption that the average propensity to consume is the same, the change of urban-rural consumption inequality is exactly the same as that of urban-rural income inequality.

Figure 1 vividly illustrates the "inverted-U shaped" change trend of urban-rural income inequality and urban-rural consumption inequality, in which curve $\mathrm{L}_{2}$ is the "inverted- $U$ shaped" change trend of urban-rural income inequality. When the urban residents' average propensity to consume is equal to that of rural residents, "inverted-U shaped" trend curve of urban-rural consumption inequality coincides with that of the urban-rural income inequality in the process of urbanization and economic development. Two curves both reach their turning points in the urbanization rate $P_{X}^{*}$ for $\mathrm{A}_{2}$. The corresponding Gini coefficients of urban-rural consumption inequality and urban-rural income inequality are equal to $G_{X}^{*}$.

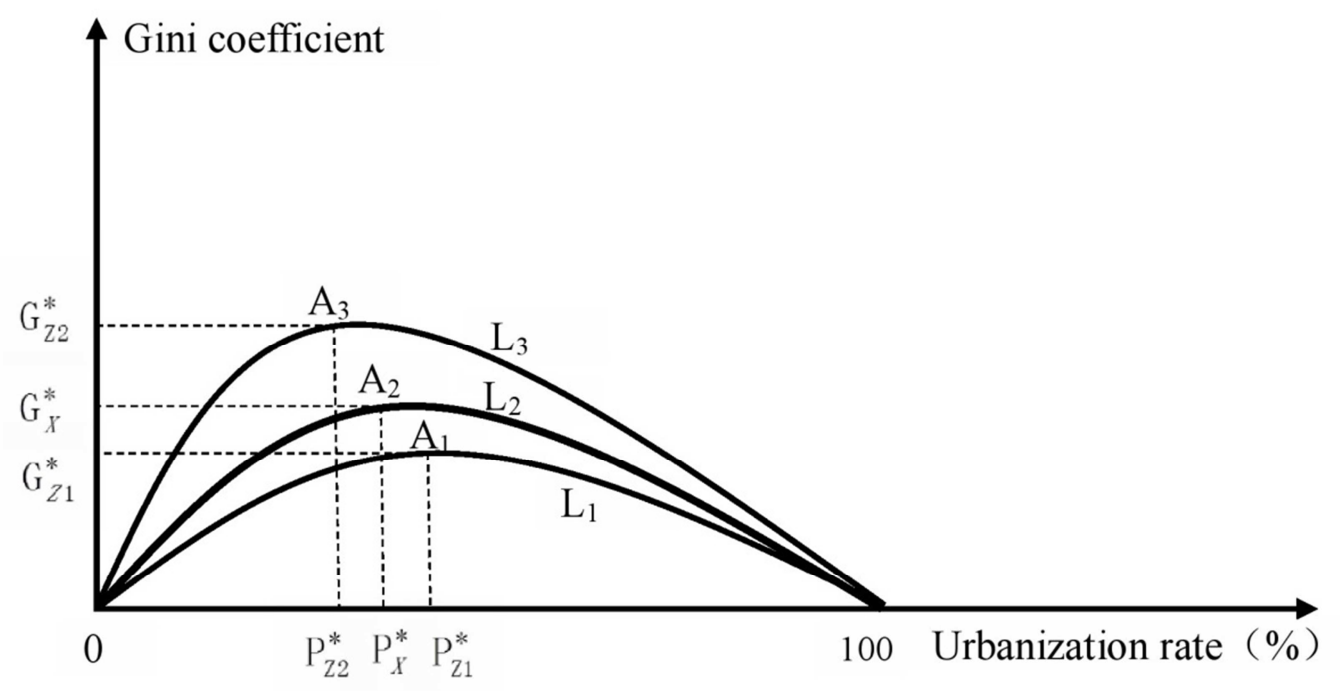

Figure 1. The relation between the urban-rural income inequality and consumption inequality on the "inverted-U" curve.

Note: Curve $\mathrm{L}_{1}$ is the inverted-U shaped trend curve of urban-rural consumption inequality under the condition that the average propensity to consume of urban residents is smaller than that of rural residents. Curve $\mathrm{L}_{3}$ is the inverted- $\mathrm{U}$ shaped trend curve of urban-rural consumption inequality under the condition that the average propensity to consume of urban residents is greater than that of rural residents. Curve $\mathrm{L}_{2}$ is the inverted-U shaped trend curve of urban-rural income inequality. It is also the inverted-U shaped trend curve of urban-rural consumption inequality under the condition that the average propensity to consume of urban residents is equal to that of rural residents.

Secondly, when the average propensity to consume of urban residents is consistently greater than that of rural residents in the process of urbanization, the "inverted-U" curve of urban-rural residents' consumption inequality is separated from their income inequality curve. The turning point of the former is always before and higher than the turning point of the latter.

$$
\text { As } \frac{c_{u}}{y_{u}}>\frac{c_{r}}{y_{r}}
$$

we have:

$$
Z=\frac{c_{u}}{c_{r}}>\frac{y_{u}}{y_{r}}=X
$$

It can be seen from equation (6) that when the average propensity to consume of urban residents is greater than that of rural residents, urban-rural consumption ratio is greater than urban-rural income ratio. Thus, equation (7) and equation (8) can be further obtained:

we have: 


$$
\begin{gathered}
P_{Z}^{*}=\frac{1}{Z^{\frac{1}{2}}+1}<\frac{1}{X^{\frac{1}{2}}+1}=P_{X}^{*} \\
G_{Z}^{*}=\frac{Z^{\frac{1}{2}}-1}{Z^{\frac{1}{2}}+1}>\frac{X^{\frac{1}{2}}-1}{X^{\frac{1}{2}}+1}=G_{X}^{*}
\end{gathered}
$$

Equation (7) and (8) show that, under assumed conditions, the urbanization rate $P_{Z}^{*}$ when the urban-rural consumption inequality is the largest is less than the urbanization rate $P_{X}^{*}$ when the urban-rural income inequality is the largest. The urban-rural consumption inequality Gini coefficient $G_{Z}^{*}$ at the turning point is greater than the urban-rural income inequality Gini coefficient $G_{X}^{*}$ at the turning point. That is to say, in the process of economic development, when the average propensity to consume of urban residents is greater than that of rural residents, the "inverted-U shaped" curve of urban-rural consumption inequality reaches its maximum firstly, and then the curve of urban-rural income inequality reaches its maximum. These two curves show different trajectories. Among them, the maximal Gini coefficient $G_{Z}^{*}$ at the top of the urban-rural consumption inequality curve is larger than the maximal Gini coefficient $G_{X}^{*}$ at the turning point of the urban-rural income inequality curve. They follow different laws of change. In comparison, the inverted-U shaped curve of urban-rural consumption inequality is larger.

In Figure 1, Curve $\mathrm{L}_{3}$ represents the "inverted-U" change trend of urban-rural consumption inequality when the average propensity to consume of urban residents is greater than that of rural residents. Obviously, Curve $\mathrm{L}_{3}$ is higher than the "inverted-U" curve $\mathrm{L}_{2}$ which represents the urban-rural income inequality. Its shape is steeper and the turning point is shifted to the upper left. The inverted- $U$ shaped curve of urban-rural consumption inequality $\mathrm{L}_{3}$ reaches the turning point at $A_{3}$, while the urban-rural income inequality $L_{2}$ reaches the turning point at $A_{2}$; The urbanization rate $A_{3}$ corresponding to the turning point of the previous curve is less than that of $\mathrm{A}_{2}$ corresponding to the turning point of the latter curve. Urban-rural consumption inequality Gini coefficient $G_{Z 2}^{*}$ at the turning point $\mathrm{A}_{3}$ of the former curve is larger than the urban-rural income inequality Gini coefficient $G_{X}^{*}$ at the turning point $\mathrm{A}_{2}$ of the latter curve.

Thirdly, on the contrary, when the average propensity to consume of urban and rural residents is consistently smaller than that of rural residents in the process of urbanization, the "inverted-U" curve of urban-rural consumption inequality and urban-rural income inequality curve are also separated. But the turning point of the former always lags behind and is lower than the turning point of the latter.

In Figure 1 , the curve $\mathrm{L}_{1}$ shows the variation trend of the "inverted-U" curve of urban-rural consumption inequality when the average propensity to consume of urban residents is smaller than that of rural residents. Curve $\mathrm{L}_{1}$ is significantly lower than the "inverted-U" curve $\mathrm{L}_{2}$ which represents urban-rural income inequality, and the turning point is shifted to the lower right. By comparison, the "inverted- $U$ " curve $\mathrm{L}_{1}$ reaches its turning point at $A_{1}$, while the urban-rural income inequality curve $L_{2}$ reaches its turning point at $\mathrm{A}_{2}$. The urbanization rate $P_{Z 1}^{*}$ at the turning point $\mathrm{A}_{1}$ of the previous curve is greater than the urbanization rate $P_{X}^{*}$ at the turning point $\mathrm{A}_{2}$ of the latter curve. Accordingly, the urban-rural consumption inequality Gini coefficient $G_{Z 1}^{*}$ corresponding to the turning point $\mathrm{A}_{1}$ is less than the urban-rural income equality Gini coefficient $G_{X}^{*}$ corresponding to the turning point $\mathrm{A}_{2}$.

Fourthly, assume that the change of urban and rural residents' consumption propensity direction is not constant in the process of urbanization. The average propensity to consume of urban residents is staggered greater or less than that of rural residents. By the same token, the urban-rural consumption inequality "inverted-U shaped" curve will be staggered above or below urban-rural income inequality "inverted-U shaped" curve. For illustration purposes, only six possible situations where the two curves intersect once ${ }^{7}$ are analyzed (as shown in Figure 2).

Figure 2-F1, 2-F2 and 2-F3 show the cases that the average propensity to consume of urban residents is firstly greater than (corresponding to the urbanization rate of 0 to $\hat{P}$ ), equal to (corresponding to the urbanization rate of $\hat{P}$ ), and then less than (corresponding urbanization rate greater than $\hat{P}$ ) that of rural residents in the process of urbanization. There may occur three forms of the relationship between the urban-rural consumption inequality "inverted-U shaped" curve and the urban-rural income inequality "inverted-U shaped" curve.

According to the previous analysis, before the urbanization rate $\hat{P}$, under the assumption that the average propensity to consume of urban residents is greater than that of rural residents, the inverted-U shaped curve of urban-rural consumption inequality appears above the inverted- $U$ shaped curve of urban-rural income inequality; When the urbanization rate is exactly $\hat{P}$, under the assumption that the average propensity to consume of urban residents is equal to that of rural residents, the urban-rural consumption inequality "inverted-U shaped" curve and the urban-rural income inequality "inverted-U shaped" curve are staggered and interlaced in $\hat{A}$; When urbanization rate is greater than $\hat{P}$, as assuming that the urban residents' average propensity to consume is less than the average propensity to consume of rural residents, the "inverted-U" curve of urban-rural consumption inequality appears on the bottom of "inverted- $U$ shaped" curve of urban-rural income inequality.

In Figure 2-F1, the urban-rural consumption inequality curve reaches the turning point $\mathrm{A}_{1}$ firstly, and then the urban-rural income inequality reaches the turning point $A_{2}$. Urban-rural consumption inequality at the turning point $A_{1}$ is greater than the urban-rural income inequality at the turning

\footnotetext{
7 The average propensity to consume of urban residents is equal to that of rural residents at the cross point.
} 
point $\mathrm{A}_{2}$. Both turning points corresponding to the urbanization rate are less than $\hat{P}$. Average propensity to consume of urban residents is greater than that of rural residents at thier turning points. In Figure 2-F2, when the urban-rural consumption inequality curve reaches turning point $\mathrm{A}_{1}$, the corresponding urbanization rate is less than $\hat{P}$. The average propensity to consume of urban residents is greater than that of rural residents at the turning point of urban-rural consumption inequality; The urbanization rate where the urban-rural income inequality reaching turning point of $\mathrm{A}_{2}$ is more than $\hat{P}$. The average propensity to consume of urban residents is less than that of rural residents at the turning point of urban-rural income inequality. In Figure 2-F3, the inverted- $U$ shaped curve of urban-rural income inequality reaches turning point $\mathrm{A}_{2}$ firstly, and then the urban-rural consumption inequality reaches turning point $A_{1}$. Urban-rural consumption inequality in turning point $A_{1}$ is smaller than urban-rural income inequality in turning point $A_{2}$. The urbanization rates corresponding to these two turning points are greater than $\hat{P}$. At their turning point, the average propensity to consume of urban residents is smaller than that of rural residents.

\section{Gini coefficient}

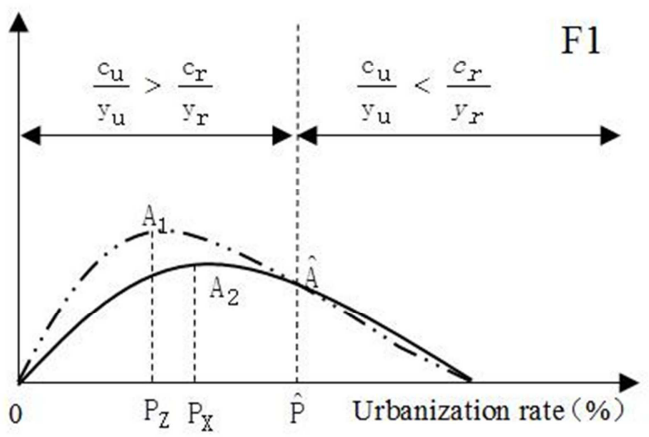

\section{Gini coefficient}

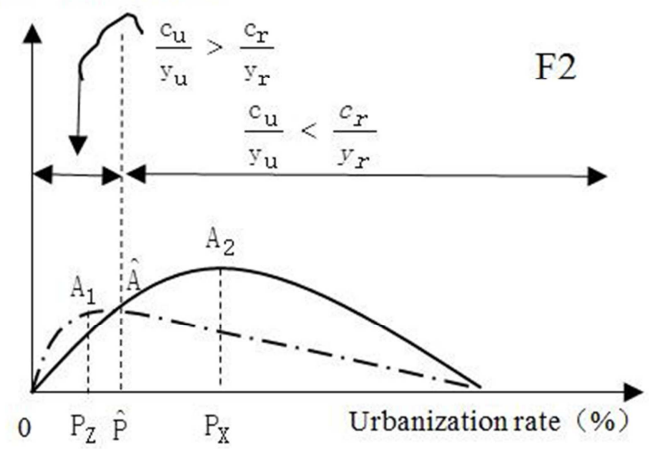

\section{Gini coefficient}

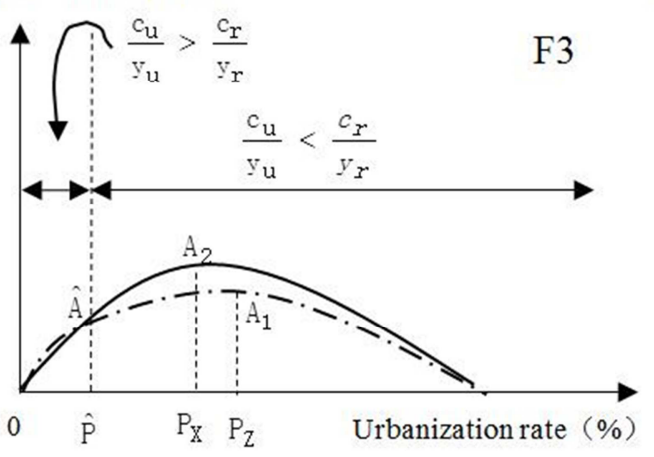

Gini coefficient

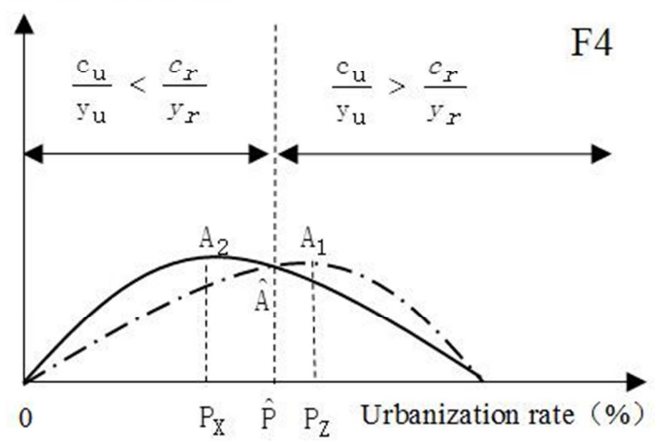

\section{Gini coefficient}

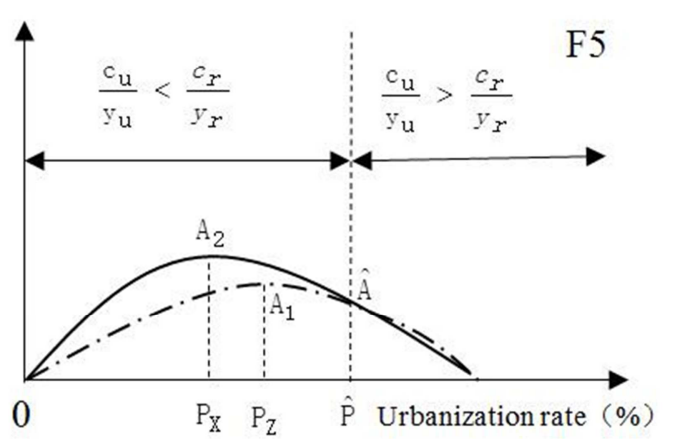

\section{Gini coefficient}

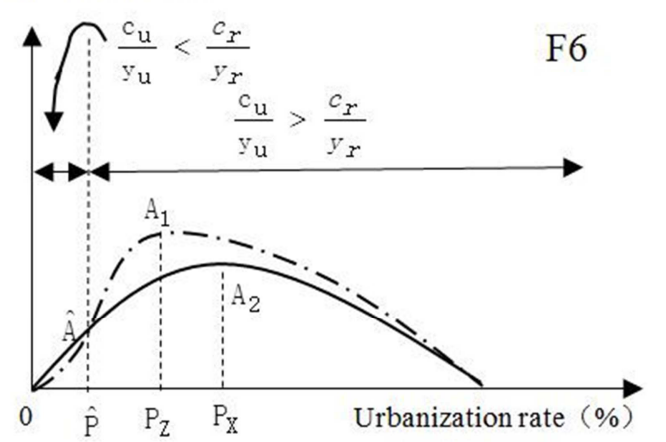

Figure 2. Six possible scenarios when the average propensity to consume of urban and rural residents is staggered only once.

Note: the dotted line represents the "inverted-U" curve of urban-rural consumption inequality, while the solid line represents the "inverted-U" curve of urban-rural income inequality. inverted-U shaped curve of urban-rural consumption inequality and that of the urban-rural income inequality staggered in point $A$, and the urbanization rate corresponding to interlacing point $A$ is $P$.

Figure 2-F4, 2-F5 and 2-F6 show the cases that urban residents' average propensity to consume is firstly less than

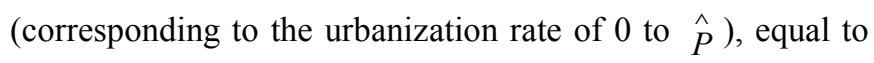


(corresponding to the urbanization rate of $\hat{P}$ ), and then greater than (corresponding urbanization rate greater than $\hat{P}$ ) that of rural residents in the process of advancing urbanization. there may occur three forms of the relationship between the urban-rural consumption inequality "inverted-U shaped" curve and the urban-rural income inequality "inverted-U shaped" curve.

Before the urbanization rate of $\hat{P}$, due to the assumption that average propensity to consume of urban residents is less than that of rural residents, the "inverted-U shaped" curve of urban-rural consumption inequality appears on the bottom of the "inverted-U shaped" curve of urban-rural income inequality; When urbanization rate exactly in $\hat{P}$, due to the assumption that average propensity to consume of urban residents is equal to that of rural residents, as a result, the urban-rural consumption inequality "inverted-U shaped" curve and the urban-rural income inequality "inverted-U shaped" curve are staggered and interlaced in $\hat{A}$; When urbanization rate is greater than the $\hat{P}$, due to the assumption that urban residents average propensity to consume is greater than the rural residents', the "inverted-U shaped" curve of urban-rural consumption inequality appears on the top of the "inverted-U shaped" curve of urban-rural income inequality.

In Figure 2-F4, the urbanization rate corresponding to the turning point $\mathrm{A}_{2}$ of the urban-rural income inequality curve is less than $\hat{P}$. The average propensity to consume of urban residents is smaller than that of rural residents at the turning point of the urban-rural income inequality; While the urbanization rate corresponding to the turning point $A_{1}$ of the urban-rural consumption inequality curve is greater than $\hat{P}$, the average propensity to consume of urban residents is greater than that of rural residents at the turning point of the urban-rural consumption inequality. In Figure 2-F5, the urban-rural income inequality curve reaches turning point $\mathrm{A}_{2}$ firstly, then the urban-rural consumption inequality curve reaches turning point $A_{1}$. Urban-rural consumption inequality at the turning point $A_{1}$ is smaller than urban-rural income inequality at the turning point $\mathrm{A}_{2}$. The urbanization rates corresponding to both turning points are less than $\hat{P}$. The average propensity to consume of urban residents is smaller than that of rural residents corresponding to the two turning points. In Figure 2-F6, the urban-rural consumption inequality curve reaches the turning point $A_{1}$ firstly, and then the urban-rural income inequality reaches the turning point $A_{2}$. Urban-rural consumption inequality at the turning point $A_{1}$ is greater than urban-rural income inequality at the turning point $\mathrm{A}_{2}$. The urbanization rates corresponding to both turning points are greater than $\hat{P}$. The average propensity to consume of urban residents is greater than that of rural residents corresponding to these two turning points.

Of course, the situation will be more complicated if we assume that the average propensity to consume of urban residents may be greater or less than the average propensity to consume of rural residents for many times in the process of urbanization. But anyway, as long as the average propensity to consume of urban residents is greater than that of rural residents during the process of urbanization, the "inverted- $U$ shaped" change curve of urban-rural consumption inequality will be above the "inverted-U shaped" change curve of urban-rural income inequality; As long as the average propensity to consume of urban residents is smaller than that of rural residents in the process of urbanization, the "inverted-U shaped" change curve of urban-rural consumption inequality is below the "inverted-U shaped" change curve of urban-rural income inequality. It is precisely because of the differences in the average propensity to consume between urban and rural areas leading to the difference of urbanization rate or economic development level corresponding to the urban-rural consumption inequality "inverted-U" curve and the urban-rural income inequality curve at the turning points. Moreover, the turning point value of urban-rural consumption inequality and urban-rural income inequality also differ in size.

Hypothesis 2: although both the urban-rural consumption inequality curve and the urban-rural income inequality curve show a general inverted-U shaped trend, they are two curves with different trends and directions of transition when the urban and rural residents' average propensity to consume is different. In the process of economic development, when urban and rural residents have different average propensity to consume, the urbanization rate (economic development level) corresponding to the turning point of the "inverted-U" curve of urban-rural consumption inequality and the "inverted-U" curve of urban-rural income inequality must be different. The corresponding urban-rural consumption inequality and urban-rural income inequality will be different too.

\section{Empirical Analysis of the Inverted-U Curve of Urban-rural Consumption Inequality}

This paper uses China's statistical data to analyze, verify and judge the correlation between the "inverted-U shaped" change trend of China's urban-rural consumption inequality and the "inverted-U shaped" change trend of urban-rural income inequality, which may be consistent with the abstract analysis in Figure 2.

\subsection{Model and Data Sources}

Econometric model (9) is used to verify that the urban-rural consumption inequality curve is inconsistent with the urban-rural income inequality curve in height caused by the difference in average propensity to consume between urban and rural residents:

$$
\Delta_{\mathrm{GINI}}=a_{0}+a_{1} A P C S+a_{2} G D P P_{-} R+a_{3} C P I+\theta
$$

Among them, $\Delta_{G I N I}$ is the difference between urban-rural consumption inequality Gini coefficient GINI $_{c}$ and urban-rural income inequality Gini coefficient GINI $I_{y}$; 
APCS is the difference between the average propensity to consume of urban residents and that of rural residents. If $A P C S$ is not equal to 0 , it indicates that the average propensity to consume of urban residents is different from that of rural residents and the urban-rural consumption ratio is different from the urban-rural income ratio. It can be seen from the analysis above that under the condition that the average propensity to consume of urban residents is greater than that of rural residents, the variation curve of urban-rural consumption inequality is higher than that of urban-rural income inequality curve. On the contrary, it may be lower than the curve of urban-rural income inequality. We can predict that the coefficient $\alpha_{1}$ of APCS is positive. Considering the impact of economic fluctuations on urban and rural consumption, we add the GDP growth rate (represented by GDP_R) and CPI to model (9) as the control variables.

In order to further verify the "inverted-U" change trend of urban-rural consumption inequality and compare it with the "inverted-U" change trend of urban-rural income inequality, we build model (10) and model (11).

$$
\begin{gathered}
\text { GINI } I_{y}=\gamma_{0}+\gamma_{1} A_{i}+\gamma_{2} A_{i}^{2}+\gamma_{3} G D P_{-} R+\gamma_{4} C P I+\eta, \mathrm{i}=1,2 \\
G I N I_{c}=\beta_{0}+\beta_{1} A_{i}+\beta_{2} A_{i}^{2}+\beta_{3} A P C S+\beta_{4} G D P_{-} R+\beta_{5} C P I+\varepsilon, \mathrm{i}=1,2
\end{gathered}
$$

Where, $A_{1}$ and $A_{2}$ are the natural logarithm of per capita GDP and the proportion of urban population (urbanization rate). The quadratic term of $A_{i}$ is added in model (10) (11) to test the "inverted-U" change trend of urban-rural income inequality and the "inverted-U" change trend of urban-rural consumption inequality in the process of urbanization (economic development). Thus, hypothesis 1 is verified. Therefore, the coefficient $\beta_{2}$ of $A_{i}^{2}$ is expected to be negative. In the case of different consumption propensities in urban and rural areas, we can analyze the difference between the turning points of urban-rural consumption inequality curve and urban-rural income inequality curve, and test the difference of urbanization rate (economic development level) corresponding to the turning points of the two curves and the difference of urban-rural consumption inequality and income inequality by comparing model (10) and model (11). Thus, hypothesis 2 is verified. In model (10) and (11), GDP growth rate GDP_R and CPI are also added as the control variables of the model.

Among the variables included in the model above, the Gini coefficient $G I N I_{c}$ of urban-rural consumption inequality can be calculated by using the "gap value method". Thus, subtract the share of urban population accounting for the total population of society from the total consumption of urban population accounting for total consumption of society. Similarly, the "gap value method" can be used to calculate the GINI $y$ of urban-rural income inequality, i.e. total income of urban population accounting for the share of total social income minus the share of urban population in total population, that is

$$
\begin{gathered}
\text { GINI }_{c}=C_{u} \times P_{u} /\left(C_{r} \times P_{r}+C_{u} \times P_{u}\right)-P_{u} /\left(P_{u}+P_{r}\right) \\
G I N I_{y}=I_{u} \times P_{u} /\left(I_{r} \times P_{r}+I_{u} \times P_{u}\right)-P_{u} /\left(P_{u}+P_{r}\right)
\end{gathered}
$$

Among them, $C_{u}$ is the per capita consumption cash expenditure of urban households, $C_{r}$ is the per capita consumption cash expenditure of rural households, $I_{u}$ is the per capita disposable income of urban households, $I_{r}$ is the per capita net income of rural households, $P_{u}$ is the number of urban population at the end of the year, and $P_{r}$ is the number of rural population at the end of the year. Other symbols have the same meaning mentioned above.

All the data used in this paper are from CEInet statistics Database. The time period is from 1985 to 2014. The statistical characteristics of each variable in the model can be seen in Table

\begin{tabular}{|c|c|c|c|c|}
\hline & Mean & Standard deviation & Minimum & Maximum \\
\hline$G I N I_{C}$ & 0.298 & 0.0362 & 0.203 & 0.352 \\
\hline$G I N I_{Y}$ & 0.234 & 0.0415 & 0.129 & 0.282 \\
\hline Average propensity to consume of urban residents & 0.782 & 0.0850 & 0.579 & 0.935 \\
\hline Average propensity to consume of rural residents & 0.596 & 0.0607 & 0.490 & 0.684 \\
\hline per capita GDP (yuan) & 13174 & 13720 & 854 & 46490 \\
\hline $\mathrm{A}_{2}(\%)$ & 36.95 & 10.11 & 23.71 & 54.77 \\
\hline$C P I(\%)$ & 5.741 & 6.54 & -1.4 & 24.1 \\
\hline
\end{tabular}
1 . It can be seen that the size and variation of each variable are within a reasonable range and there is no outlier.

Table 1. Statistical characteristics of each variable.

Data source: Calculated by the datas come from CEInet statistics Database. 


\subsection{Model Estimation Results and Analysis}

In Table 2, regression (1) is the result of OLS estimation on model (9), which is used to illustrate the influence of difference between the average propensity to consume of urban residents and that of rural residents on the relative height of urban-rural consumption inequality curve and urban-rural income inequality curve. Regression (2) (3) is the result of OLS estimation on model (10). The dependent variable is the Gini coefficient of urban-rural income inequality and the independent variable are the natural logarithm of per capita GDP, the proportion of urban population and their quadratic term. Regression (2) (3) is used to test whether the urban-rural income inequality presents an "inverted-U" change that first increases and then decreases. Regression (4) (5) is the result of OLS estimation on model (11), the dependent variable is the Gini coefficient of urban-rural consumption inequality, and the independent variable are the natural logarithm of per capita GDP, the proportion of urban population, and their quadratic terms to verify hypothesis 1 . Thus, in the case of the average propensity to consume of urban residents is different from that of rural residents, the urban-rural consumption inequality promoted by urbanization presents an inverted-U shaped trend following the improvement of economic development level.

By comparing per capita income and the proportion of urban population at the turning points of urban-rural consumption inequality curve and urban-rural income curve calculated in regression (4) and regression (2) as well as regression (5) and regression (3), hypothesis 2 can be verified. Thus, in the case of the average propensity to consume of urban residents is different from that of rural residents, the urban-rural consumption inequality curve and the urban-rural income inequality curve are two similar but different trend curves. These two curves have different values and different urbanization rate (economic development level) at their turning point. In addition, GDP growth rate and CPI are added as control variables in each regression model.

Following conclusions can be obtained from the regression results in Table 2:

First, the height of urban-rural consumption inequality is inconsistent with the urban-rural income inequality curve. It can be seen from the regression (1) that the estimated coefficient of the difference between the average propensity to consume of urban and that of rural residents is 0.35493 , which is significantly positive at the $1 \%$ significance level. It shows that under the condition that the average propensity to consume of urban residents is greater than that of rural residents, the urban-rural consumption inequality is greater than the urban-rural income inequality; Under the condition that the average propensity to consume of urban and rural residents is less than that of rural residents, the urban-rural consumption inequality is less than the urban-rural income inequality; the height of urban-rural consumption inequality curve is inconsistent with that of urban and rural income inequality curve if. the average propensities to consume of urban residents and rural residents are different.

Second, the variation trend of urban-rural consumption inequality and urban-rural income inequality is roughly the same. Both of them show an inverted-U shaped trend. The estimated coefficients of the natural logarithm of per capita GDP in regression (2) and (4) are 0.26633 and 0.31567 respectively, both of which are significant at the $1 \%$ significance level; The estimated coefficients of squared natural logarithm of per capita GDP were -0.01362 and -0.01752 , both of which are significant at the $1 \%$ significance level. It shows that urban-rural consumption inequality and urban-rural income inequality both show inverted-U shaped change trend of firstly rising and then falling in the process of economic development. The estimated coefficients of the proportion of urban population in regression (3) and (5) are 0.03106 and 0.02771 respectively, both of which are significant at the $1 \%$ significance level; The estimated coefficients of the square of urban population proportion are -0.00036 and -0.00035 respectively, both of which are significant at the significance level of $1 \%$. It shows that the urban-rural consumption inequality promoted by urbanization is the same as the urban-rural income inequality, presenting inverted-U shaped change trend of firstly rising and then falling. So hypothesis 1 is confirmed.

Table 2. OLS estimation result of model (9)-(11).

\begin{tabular}{|c|c|c|c|c|c|}
\hline \multirow{2}{*}{ Variables } & (1) & (2) & (3) & (4) & (5) \\
\hline & $\Delta_{\mathrm{GINI}}$ & GINI $_{\mathbf{y}}$ & GINI $_{y}$ & GINI $_{c}$ & GINI $_{c}$ \\
\hline$A_{1}$ & & $\begin{array}{l}0.26633 * * * \\
(7.33317)\end{array}$ & & $\begin{array}{l}0.31567 * * * \\
(9.45595)\end{array}$ & \\
\hline$A_{1}^{2}$ & & $\begin{array}{l}-0.01362 * * * \\
(-6.61295)\end{array}$ & & $\begin{array}{l}-0.01752 * * * \\
(-8.21531)\end{array}$ & \\
\hline$A_{2}$ & & & $\begin{array}{l}0.03106^{* * *} \\
(12.38634)\end{array}$ & & $\begin{array}{l}0.02771^{* * *} \\
(10.78344)\end{array}$ \\
\hline$A_{2}^{2}$ & & & $\begin{array}{l}-0.00036^{* * *} \\
(-11.30880)\end{array}$ & & $\begin{array}{l}-0.00035^{* * *} \\
(-10.23294)\end{array}$ \\
\hline$A P C S$ & $\begin{array}{l}0.35493 * * * \\
(48.62798)\end{array}$ & & & $\begin{array}{l}0.17103 * * * \\
(2.87148)\end{array}$ & $\begin{array}{l}0.15686^{*} \\
(1.94543)\end{array}$ \\
\hline$G D P_{-} R$ & $\begin{array}{l}-0.00021 \\
(-0.58173)\end{array}$ & $\begin{array}{l}0.00258^{* *} \\
(2.25159)\end{array}$ & $\begin{array}{l}0.00157 \\
(1.70169)\end{array}$ & $\begin{array}{l}0.00279 * * * \\
(3.33716)\end{array}$ & $\begin{array}{l}0.00204 * * \\
(2.12408)\end{array}$ \\
\hline CPI & 0.00010 & $-7.22 \mathrm{e}-07$ & $0.00151^{* * *}$ & -0.00008 & $0.00101^{* *}$ \\
\hline
\end{tabular}




\begin{tabular}{|c|c|c|c|c|c|}
\hline \multirow{2}{*}{ Variables } & (1) & $(2)$ & (3) & $(4)$ & $(5)$ \\
\hline & $\Delta_{\text {GINI }}$ & GINI $_{y}$ & GINI $_{\mathbf{y}}$ & GINI $_{c}$ & GINI $_{\mathbf{c}}$ \\
\hline & $(0.62717)$ & $(-0.00141)$ & $(3.35435)$ & $(-0.20041)$ & $(2.08685)$ \\
\hline Constant & $\begin{array}{l}-0.00013 \\
(-0.03474)\end{array}$ & $\begin{array}{l}-1.06250 * * * \\
(-6.75675)\end{array}$ & $\begin{array}{l}-0.41406 * * * \\
(-8.83134)\end{array}$ & $\begin{array}{l}-1.15638^{* * *} \\
(-9.30274)\end{array}$ & $\begin{array}{l}-0.26791 * * * \\
(-4.35565)\end{array}$ \\
\hline $\mathrm{F}$ & 956 & 48.17 & 80.01 & 58.68 & 45.63 \\
\hline $\mathrm{R}^{2}$ & 0.99102 & 0.88515 & 0.92755 & 0.92439 & 0.90482 \\
\hline $\operatorname{Adj}-R^{2}$ & 0.990 & 0.867 & 0.916 & 0.909 & 0.885 \\
\hline Per capita GDP at turning point (yuan) & - & 17647 & - & 8158 & - \\
\hline Urbanization rate at turning point (\%) & - & - & 43.40 & - & 39.55 \\
\hline
\end{tabular}

Note: (1) "*" means significant at the $10 \%$ level; “**” means significant at the $5 \%$ level; “***” means significant at the $1 \%$ level. (2) t-test value is in parentheses.

Third, the economic development level or urbanization rate corresponding to the turning points of the inverted-U shaped change curves of urban-rural consumption inequality and urban-rural income inequality is different. Using the result of regression (2), let the first derivative of the Gini coefficient of urban-rural income inequality on the natural logarithm of per capita GDP equal to zero, the corresponding per capita GDP is 17,647 yuan which is equivalent to the income level around 2006 at the turning point of urban-rural income inequality Gini coefficient "inverted-U" curve. Using the result of regression (4), let the first derivative of the Gini coefficient of urban-rural consumption inequality on the natural logarithm of per capita GDP equal to zero, the corresponding per capita GDP is 8158 yuan which is equivalent to the income level around 2000 at the turning point of urban-rural consumption Gini coefficient "inverted-U" curve. It can be seen that the level of economic development corresponding to the turning point of the urban-rural consumption inequality curve is lower than that of the urban-rural income inequality curve.

Using the result of regression (3), let the first derivative of the Gini coefficient of urban-rural income inequality on the proportion of urban population equal to zero, the corresponding proportion of urban population is $43.4 \%$ which is equivalent to the urbanization level around 2006 at the turning point of urban-rural income Gini coefficient "inverted-U" curve. Using the result of regression (5), let the first derivative of the Gini coefficient of urban-rural consumption inequality on the proportion of urban population equal to zero, the corresponding proportion of urban population is $39.55 \%$ which is equivalent to the urbanization level around 2002 at the turning point of urban-rural consumption Gini coefficient "inverted-U" curve. This shows that the urbanization rate corresponding to the turning point of urban-rural consumption inequality is lower than that of urban-rural income inequality. In other words, from the perspective of time, the former occurs earlier than the latter.

Fourth, the change relationship between the "inverted-U" curve of urban-rural consumption inequality and that of urban-rural income inequality is consistent with the description in Figure 2-F1. Figure 3 shows the change curve of average propensity to consume of urban and rural residents, the "inverted-U" curve of urban-rural consumption inequality and that of urban-rural income inequality. Figure 3 indicates the influence of different average propensity to consume of urban and rural residents on urban-rural income inequality and urban-rural consumption inequality change trend. Before 2011, the average propensity to consume of urban residents gradually decreased, but was greater than that of rural residents for a long time. The reason may be that the income and social security level of rural residents are too low, which makes the long-term growth of rural residents' consumption slow. In addition, the simplex supply of rural consumer goods and the lack of convenience in purchasing goods are also the reasons for the low average propensity to consume of rural residents. With the enhancement of rural residents' income and social security and the improvement of the supply of consumer goods, the average propensity to consume of rural residents and that of urban residents appeared staggered in around 2012. The former gradually increased and exceeded the latter after 2012. These features conform to the situation of Figure 2-F1, 2-F2 and 2-F3.

Accordingly, urban-rural consumption inequality curve and urban-rural income inequality curve staggered in 2012. By comparing regression (2) and regression (4) as well as regression (3) and regression (5), it can be found that the turning point of urban-rural consumption inequality curve appeared in 2000-2002, while urban-rural income inequality curve appeared in 2006. The Gini coefficient at the turning point of the urban-rural consumption inequality in 2000-2002 was about 0.33 , larger than the Gini coefficient at the turning point of the urban-rural income inequality 0.28 in 2006 . These features are similar to those depicted in Figure 2-F1. Promoted by urbanization, as the average propensity to consume of urban residents is greater than that of rural residents, the "inverted-U" curve of urban-rural consumption inequality and the curve of urban and rural income inequality reached turning points in turn In the process of economic development. The turning point value of the urban-rural consumption inequality curve is 0.33 (equivalent to the urban-rural consumption inequality of $\mathrm{A}_{1}$ point in Figure 2-F1) which is larger than the turning point value 0.28 of urban-rural income inequality curve (equivalent to the urban-rural income inequality of $\mathrm{A}_{2}$ point in Figure 2-F1). After 2012 (the urbanization rate was $52.57 \%$, equivalent to $\hat{P}$ in Figure 2-F1), the urban-rural consumption inequality curve is lower than the urban-rural income inequality curve as the average propensity to consume of urban residents is smaller than that of rural residents.

Thus, hypothesis 2 is confirmed. In the case that the average propensity to consume of urban and rural residents are different, the urbanization rate (economic development level) and Gini coefficient values corresponding to the turning points of the 
"inverted-U" curve of urban-rural consumption inequality and urban-rural income inequality curve are different.

Fifth, from the perspective of control variables, the coefficients of GDP growth rate are all positive (1) is negative but not significant) in the regression $(2) \sim(5)$, which may be caused by the greater influence of economic growth on the growth of urban residents' income and consumption; The coefficients of consumer price index are not certain, so the impact of consumer price index on urban-rural income inequality and urban-rural consumption inequality is not clear.

In conclusion, empirical results show that the urban-rural consumption inequality indeed presents inverted-U shaped trend that rises first and then falls with the increase of urbanization rate or income level. Under the situation that the average propensity to consume of urban and rural residents are different, the variation of urban-rural consumption inequality is bound to be separated from the variation of urban-rural income inequality. The former following inverted-U shaped curve similar but not the same to the latter. Specific to the situation of China in recent years, the turning point of the "inverted-U" curve of urban-rural consumption inequality appears in 2000-2002, while the turning point of the "inverted-U" curve of urban-rural income inequality appears in 2006. The economic development level or urbanization rate corresponding to the turning point of the former curve is lower than that of the latter curve, but the inequality value at the turning point of the former curve is larger.

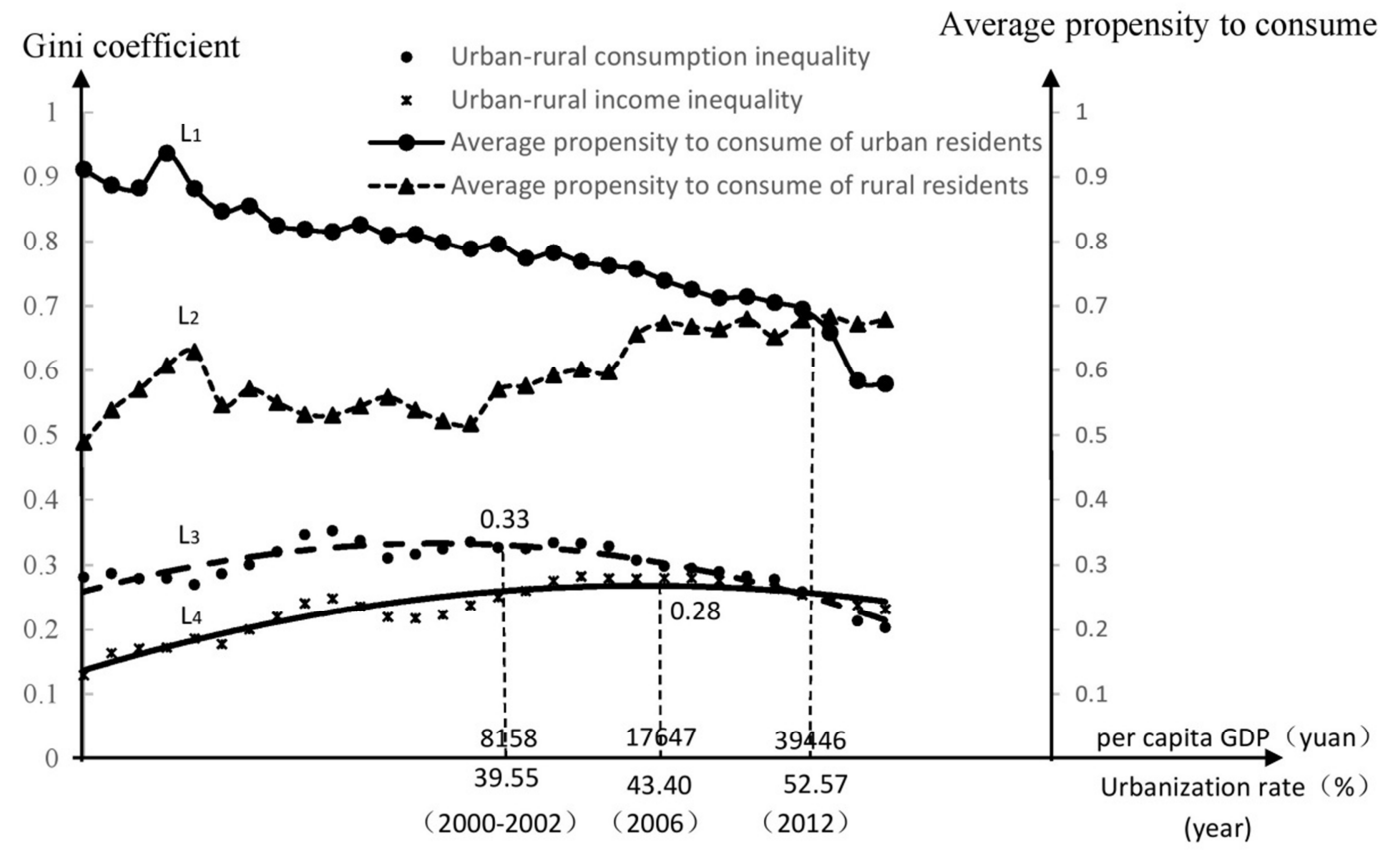

Figure 3. Change curves of average propensity to consume of urban and rural residents and "inverted-U" curves of urban-rural consumption inequality and urban-rural income inequality.

Notes:(1) $\mathrm{L}_{1}$ is the change curve of the average propensity to consume of urban residents, $\mathrm{L}_{2}$ is the change curve of the average propensity to consume of rural residents, $\mathrm{L}_{3}$ is an inverted- $U$ shaped curve of urban-rural consumption inequality, and $\mathrm{L}_{4}$ is an inverted-U shaped curve of urban-rural income inequality; (2) The average propensity to consume of urban residents is the ratio of the per capital cash expenditure of urban households to their per capital disposable income; The average propensity to consume of rural residents is the ratio of the per capital cash expenditure of rural households and their per capital net income.

Data source: Calculated by the datas come from CEInet statistics Database.

\section{Conclusions and Policy Recommendations}

The variations of urban-rural consumption inequality and urban-rural income inequality have the same internal mechanism. In the process of economic development, while the urban-rural income inequality follows the change of "inverted-U shaped", the urban-rural consumption inequality appears "inverted-U shaped" change too. After examining the influence of the average consumption propensity in urban and rural areas, this paper finds that the variation curves of urban-rural consumption inequality and urban-rural income inequality are actually two different curves, although showing a similar trend. It is precisely because that the average propensities to consume of urban and rural residents are different. The heights of urban-rural consumption inequality curve and urban-rural income inequality curve during the economic development process of urbanization are different. Their corresponding urbanization rate (economic development level) at their turning points and the turning point values of these two curves are also different. Empirical test results based on the data of China show that the urban-rural consumption inequality is indeed an inverted- $U$ shaped trend similar to income inequality that rises and then falls with the increase of income level. The turning point of the urban-rural consumption inequality curve appears between 2000 and 2002, which is 4 to 6 years before the turning point of the urban-rural income 
inequality in 2006. The urbanization rate (economic development level) is relatively lower when the turning point of urban-rural consumption inequality occurs. According to the analysis of the current situation in China, although urban-rural consumption inequality and urban-rural income inequality has been over the turning point and gradually began to shrink, the current level of urban-rural consumption inequality and urban-rural income inequality in China are still high using the Gini coefficient indicator. The proportion of them in total consumption and total income are relatively high too (about $50 \%$ ). In the case of relatively high urban-rural income inequality, reducing the urban-rural consumption inequality through a series of policies and measures is of great significance to improving the actual welfare of residents, maintaining the balance between urban and rural consumption, raising the level of household consumption, promoting economic growth and realizing the goal of building a moderately prosperous society in all respects.

According to the analysis of this paper, in order to further narrow the urban-rural consumption inequality and improve the overall level of social consumption, on the one hand, we should fundamentally improve the level of economic development and the quality of economic growth because income is the most basic factor that determines consumption. On the other hand, various measures should be taken to increase the average propensity to consume of urban and rural residents, especially rural residents. Only in this way can the consumption level of the whole society be promoted and become the new driving force of economic growth in the new era.

First, it can be seen from Figure 3 that the urban-rural income inequality is still large in China, and the current rural income is far lower than that of urban residents. Therefore, in order to improve the overall consumption, it is necessary to increase the income of farmers so that rural residents can and will be willing to spend. It is also the most effective way to increase the consumption of rural residents. For example, we can continue to support agricultural products prices, deepen targeted poverty alleviation measures, and stabilize and raise the income expectations of rural residents.

Second, China's economic development has passed the per capita GDP and urbanization rate corresponding to the turning point of urban-rural consumption inequality calculated by regression (4) and (5). China's current urban-rural consumption inequality has shown a downward trend, therefore, the urbanization process should be continued. While promoting urbanization, it is necessary to facilitate the surplus rural labor force to seek jobs in cities and towns, establish an employment information service platform, truly eliminate the differences of "dual household registration system", guide farmers to be integrated into urban life as citizens, and protect transferred population's basic or equal rights and interests.

Thirdly, from the analysis of the second part of this paper, it can be found that the low rural social security is an important reason for the low average propensity to consume of rural residents. Therefore, it is necessary to establish and improve the rural social security system so that rural residents can consume without worries and dare to consume using their future income. For example, improve rural medical care and pension systems so that farmers can have a roof over the head, their sick can be treated and the elderly can be taken care of. Also, we can continue to increase rural residents' transfer payments and help those in need.

Fourthly, it can also be found from the analysis of the second part of this paper that the "diligent and thrifty" consumption habit restricts rural consumption power. Therefore, in order to improve the consumption level of rural residents, it is also reasonably to stimulate rural consumption. For example, continue to promote internet finance and home appliances in rural areas, so that rural residents can buy home appliances without leaving their homes. We can provide purchase subsidies for large mechanical products such as harvesters and publicize and popularize advanced agricultural products.

Fifth, of course, it is also important to raise the consumption level of urban residents. The second part of this paper shows that the current urban residents are limited by the structure of consumer goods, which makes the average propensity to consume of urban residents low. In order to improve average propensity to consume and consumption level of urban residents, we should improve product quality, research and develop innovative products, put out the urban poverty line and eliminate urban poverty, improve the consumption financial mechanism and so on.

\section{References}

[1] Chen zongsheng. (1991). Income distribution in economic development, Shanghai people's publishing house, Shanghai sanlian bookstore.

[2] Chen zongsheng. (1994). "step trapezoidal variation of inverted-U curve", economic research, no. 5.

[3] Chen zongsheng. (2000). income distribution, poverty and unemployment, nankai university press.

[4] Keynes, J. M. (1936), General Theory of Employment, Interest and Money, Harcourt Brace \& Company.

[5] Duesenberry, J. S. (1949), Income, Saving and Theory of Consumer Behavior, Harvard University Press.

[6] Modigliani, F. \& R. Brumberg (1954), "Utility analysis and the consumption function: An interpretation of cross-section data", in: K. E. Kurihara (ed), Post-Keynesian Economics, Rutgers University Press.

[7] Friedman, M. (1957), Theory of the Consumption Function, Princeton University Press.

[8] Li guiqian. (2013). Price, income gap and consumer demand, journal of shandong normal university (humanities and social sciences edition), no. 4.

[9] Flavin, M. A. (1981), "The adjustment of consumption to changing expectations about future income", Journal of Political Economy 89 (5): 974-1009. 
[10] Lin wenfang. (2011). Analysis of the relationship between the consumption structure and income of urban and rural residents in county regions, statistical research, no. 4.

[11] Tian shufang. (2015). Grey correlation analysis of urban residents' income and consumption in anhui province, journal of hebei north university (social science edition), no. 1.

[12] Fang songhai Wang nong \& Huang hanquan. (2011). Research on increasing farmers' income and expanding rural consumption, management world, no. 5.

[13] Zhang qiuhui \& Liu jinxing. (2010). Influence of Chinese rura residents' income structure on their consumption expenditure behavior -- based on the panel data analysis from 1997 to 2007, China rural economy, no. 4.

[14] Hou Shian \& Zhao Henan. (2012). Influence of the composition of income sources of urban and rural residents on their consumption behavior, journal of zhongnan university of economics and law, no. 6.

[15] Xu hui-qi \& Li jingqiang. (2009) Effects of different income sources on rural residents' consumption and countermeasures, economic horizon, no. 3 .

[16] Fang fuqian \& Zhang yanli. (2011). Analysis of marginal consumption propensity and changing trend of different income of urban and rural residents, finance \& trade economics, no. 4.

[17] Zhou yunbo. (2009). Changes in urbanization, urban-rural gap and overall income gap across China -- empirical test of inverted-U shaped hypothesis of income gap, economics (quarterly), no. 4.

[18] Zhong yongjian \& Xiao liang. (2007). Analysis on average consumption tendency and demand income elasticity of rural residents in China, rural economy, no. 1.

[19] Zhang zhiqiang. (2007). Empirical research on the average propensity to consume of urban residents in China - regression analysis based on logit transformation, contemporary finance and economics, no. 8.

[20] Cai derong, Wu qinqin \& Wan jianyong. (2009). Empirical research on the influencing factors of the average propensity to consume of Chinese residents, consumer economy, no. 3 .

[21] Hang bin. (2010). "why the average consumption tendency of urban residents continues to decline-an empirical analysis based on the formation of consumption habits", journal of quantitative economy, technology and economic research, no. 6.
[22] Peng zhiyuan \& Kang pi-ju. (2012). Research on the average propensity to consume of urban residents in China, journal of yunnan university of finance and economics, no. 1.

[23] Zhu Chen. (2012). The dynamic correlation between income and consumption gap between urban and rural residents-based on the empirical data from 1992 to 2009, financial science no.8.

[24] Peng dingyun \& Chen weiyi. (2014). A study on income distribution based on consumption gap index, journal of zhongnan university of economics and law, no. 2 .

[25] Wu di \& Huo xuexi. (2010). An empirical study on the interaction between the consumption gap and income gap between urban and rural residents, agricultural technology and economy, no. 8 .

[26] Zeng guoan \& Hu jingjing. (2008). On the changes of China's urban-rural income gap and its impact on the consumption level of urban and rural residents since the late 1970s, economic review, no. 1 .

[27] Ao qin \& Zheng xungang. (2005). Narrowing the income gap between urban and rural residents and expanding rural residents' consumption demand, rural economy, no. 4.

[28] Liu jianguo. (1999). Analysis on the causes of low consumption tendency of farmers in China, economic research, no. 3 .

[29] Tao chuanping. (2001). Causes and countermeasures of China's sluggish consumer market, shandong social science, no. 5.

[30] Zang xuheng \& Sun wenxiang, (2003). The consumption structure of urban and rural residents: a comparative analysis based on ELES model and AIDS model, journal of shandong university (philosophical and social science edition), no. 6 .

[31] Tian qiusheng. (2001). Reasons for the shrinking consumer demand in China in the late 1990s, journal of lanzhou business school, no. 3 .

[32] Zhong hong \& Dai minle. (2006). Measures to increase consumer spending. China statistics, no. 4.

[33] Robinson, S. (1976), "A note on the U hypothesis relating income inequality and economic development", American Economic Review 66 (3): 437-440.

[34] Rauch, J. E. (1991), "Economic development, urban underemployment, and income inequality", Canadian Journal of Economics 26 (4): 901-918. 